\title{
Designing for Children's Outdoor Play
}

\author{
Jon Back ${ }^{1}$, Caspar Heeffer ${ }^{2}$, Susan Paget ${ }^{3}$, Andreas Rau ${ }^{2}$, \\ Eva Lotta Sallnäs Pysander ${ }^{2}$, Annika Waern ${ }^{1}$ \\ Department of Informatics and \\ Media, \\ Uppsala University \\ Uppsala, Sweden \\ Urban and Rural Development, \\ Swedish University of \\ Agricultural Sciences \\ Uppsala, Sweden \\ jon.back|annika.waern@im.uu.se \\ Media Technology and \\ Interaction Design, \\ Royal Institute of Technology \\ Stockholm, Sweden \\ susan.paget@slu.se \\ cjhhe|arau|evalotta@kth.se
}

\begin{abstract}
Children's outdoor play is fluent and fluctuating, shaped by environmental features and conditions. The article reports on a project where interaction designers and landscape architects work together to fuse their knowledge into working solutions for integrating interactive play in outdoor environments. We report on a schoolyard trial, where interactive play technology was installed as an integral part of a schoolyard environment, and discuss the interplay between technology and the environment that was partly natural forest and partly constructed playground. We highlight in particular the importance of the adaptability of the natural environment, how the combination of interactive technology and natural environment can contribute to the versatility of play activities, and how the interactive technology can both be useful for presenting invitations to play in such adaptable places, and enhance the adaptability for play in otherwise impoverished places.
\end{abstract}

\section{Author Keywords}

outdoor play; playscape; interactive play technology; landscape architecture

\section{INTRODUCTION}

Outdoor play is typically considered an essential, healthy and desirable activity for children [5], especially in its capability of encouraging physical activity. Yet, studies have shown that children spend less time outdoors than previous generations [6]. While the impact of this on children's physical activity has received much attention [27], its impact on imaginary play may be even more severe $[6,32]$; the form of play that Piaget considered most beneficial for the child's cognitive and social development [25].

Permission to make digital or hard copies of part or all of this work for personal or classroom use is granted without fee provided that copies are not made or distributed for profit or commercial advantage and that copies bear this notice and the full citation on the first page. Copyrights for thirdparty components of this work must be honored. For all other uses, contact the Owner/Author.

Copyright is held by the owner/author(s).

DIS 2016, June 04-08, 2016, Brisbane, QLD, Australia

ACM 978-1-4503-4031-1/16/06.

http://dx.doi.org/10.1145/2901790.2901875
One reason for the decline in outdoor play is the increased access to screen-based activity in the form of $\mathrm{TV}$, Internet and computer games [26, 32]. But in addition, the urban landscape is designed as if children would only play in designated playgrounds, designed to offer safety and seclusion.

Incorporating technology in the outdoor environment is a potential way to combine the social and physical advantages of classical outdoor play with the appeal of computer games [26, 32, 29], thus making outdoor play more attractive to children again [32]. An interactive playground is commonly defined as a space in which physical play objects are augmented with digital technology that stimulate play [32].

The project DigiFys seeks to go beyond this approach, to develop play landscapes with integrated interactive components. It is a collaboration project between interaction designers and landscape architects, and while

semi-generic, the approach strives to make interactive technology completely integrated in a specific landscape. Hence, understanding the affordances and opportunities offered by the place itself is an essential part of the design process, as is understanding the lifestyle and culture of the children residing in the area.

\section{BACKGROUND}

\section{Children's Outdoor Play}

Outdoor play tends to be more mobile and physical than indoors play, but follows the same general development patterns [20]. Piaget's theories of play as instrumental in cognitive development [25] and Parten's models of social play development [24] constitute early but useful models of play development that apply also to outdoor play. Detailed studies have focused on the effects on play by playground design (see Barbour [1] for a literature overview). In general, children's outdoor play is revered as "a natural and critical part of a child's healthy development" [6] through which children get physically apt but also learn important skills such as social competence and risk assessment, they also get to use their creativity.

Access to nature and natural materials is often considered a crucial part of the outdoor experience [36]. Talbot and Frost [33] coined the term 'Playscape' as a way to think about 
how a particular landscape can afford play and what they call "magical thinking". In her detailed study of outdoor play in a natural forest, Fjørtoft [10] discusses how the shrubbery affords both hide-and-seek as well as imaginative play (e.g. playing 'house'), whereas more sturdy trees would afford climbing and open spaces running and games of 'tag'. Retaining natural landscape environments in for example school grounds has been found to increase the amount of play activities pursued by children in general, not only in the natural landscape but also in adjacent hard-made areas [19]. Different kinds of loose material have been found to be important for children's play and development $[20,21]$, and the temporal aspect of outdoor play is also important, with variable conditions such as wind, snow, sun, dusk, heat and cold [20]. Playing outdoors provides a varied environment with many levels of challenges that develop both motor and sensory abilities [31].

Interventions such as planting areas with both natural and horticultural species in the schoolyard have been used as a way to improve the physical wellbeing of the children, and change the culture of play in the school grounds [2]. Herrington and Studtmann [14] used landscape interventions to redesign play at a schoolyard, e.g. by installing a sequence of stepping-stones that encouraged children to move in previously unused areas. A particularly interesting observation from this study was how the mere act of planting some bushes moved play out of the fixed installations into two 'houses' formed by the bushes, perceived as suitable for imaginative play by the children. The authors note that the children that were dominant in this play activity were another group than those who dominated the physical activities afforded by the ordinary fixed installations. Presenting a varied landscape is thus not only a way to afford multiple forms of play, but also a way to create more flexibility in the social roles among the children. It may also serve to counter gendered differences in the amount of outdoor play [12].

\section{Designing interactive technology for outdoor play}

Most interaction design products for outdoor play target playgrounds and schoolyards. There is also a distinct focus on encouraging physical play through game challenges, over designs encouraging imaginative play. An example of this are the range of interactive products offered by Lappset $^{1}$, such as the interactive ball wall Sunu. The Sunu wall provides feedback through LED lights when a ball is kicked against the wall; it can be configured to present different challenges, and it is possible to play against other Sunu wall installations around the world. Sturm et al [32] suggest that such installations should afford simultaneous interaction by multiple players, be simple to use, and while not necessarily be games, still offer an interesting challenge to explore.

\footnotetext{
1 http://www.lappset.com/global/en/Products/InteractivePlay
}

Research projects have to a larger extent placed focus on supporting open-ended and creative play through more open-ended designs. Rosales [28] used evocative design experiments to elicit free play in young children. The SmartGoals [35] are simple poles that form a goal that light up when something is passing between them. FlashPoles [32] are poles that light up when buttons are pushed or rotated. Some mobile technology has also been proposed such as the Ledball [32] and the Morels [15]. The focus in these projects has been on supporting open-ended play rather than implementing specific game challenges. De Valk et al. [7] propose a design strategy towards what they call open-ended play; play activities that are guided, but not constrained, by the designed artefacts. According to the authors, players that engage with open-ended installations go through a three-stage process of accepting the invitation, exploring the opportunities and subsequently immersing in the play activity [7, 8]. With a sufficiently rich and suggestive installation, the play activity may shift back and forth between exploration and immersion. Very similar design principles have been articulated for playful art installations in public space [23].

These design approaches have in common that they focus on the interactive technology as such. The crucial role of the playscape, nature and natural materials, is seldom taken into account in the design approaches towards playful interactive technology.

\section{Interactive Playgrounds}

Work in the field of playgrounds, where interactive play technology is considered in a spatial context, is still often based on user studies with specific interactive play objects. The influence of the environment plays a subordinate role in such work. Especially, the user studies on interactive playgrounds rarely take place in an actual outdoors playground setting but rather in gyms, [8, 9, 35] or even lab settings [34], neglecting the influence of the environment on play. Many studies on interactive playgrounds in outdoor settings also primarily focus on the digital props and the isolated play with them $[16,19,30]$.

Seitinger et al. [29] focus on the relationship between children and the play environment as mediated by animated playground props. They examine the ability of such interactive objects to "enhance open-ended and physically active play in playgrounds". As consequences of using interactive elements in playgrounds, the authors mention increased physical activity, high engagement level of the children and the exploratory nature of the activities performed. The spatial component of play is also explicitly considered in the Water Games presented by Pare's et al. [22]. Their concept involves the entire environment and features interactive water fountains that can be invoked by groups of users holding hands while moving around the fountains. Finally, a recurring concept in interactive playgrounds is interactive tiles that give light feedback using built in LEDs. This approach of using modular 
building blocks that together form a game [13] is used in many interactive playground designs, including GlowSteps [9], The Body Games [18], and Play-ware [13].

\section{DIGIFYS - DESIGNING FOR CHILDREN'S OUTDOOR PLAY}

DigiFys is a long-term collaboration between landscape architects and interaction designers, with the goal to develop children's play environments. Capitalizing on both interaction design and landscape design, the long-term goals of the DigiFys project proposes to focus on children's immediate surroundings - playing 'close to home'. The reported study is targeting a schoolyard environment, which is an equally important but slightly more coherent environment, as its main purpose is to host children whereas the environment close to home must cater for both children and adult activities.

\section{Design approach}

The project uses a multi-disciplinary approach, combining elements both from landscape architecture and interaction design. These methods are at the same time complementary and sometimes conflicting. Since a full landscape design is costly and permanent, the landscape architects work with sketches and prototypes as main tools in illustrating landscape concepts. The design process has been guided by walking tours including children-led walks [4] at their local play areas. Several workshops have also been organized in situ with children and teenagers, with the purpose of eliciting an understanding of places of importance and neglect in their current play environments.

In parallel, the interactive technology has begun to take shape. The design was inspired by the walking tours and design workshops, but in order to develop interactive solutions with some level of generality, it needed to follow a much more artefact- and technology-centred process during design and development. The goal of this process was to develop fully functional prototypes, gradually working towards commercially viable semi-generic solutions in collaboration with a commercial project partner.

The prototypes presented below were developed in a fairly standard iterative design process. The first functional prototypes were trialled with invited children in a lab environment staged to mimic an outdoor location, and focussed on creating design solutions that would support open-ended play [7]. After this, a second round of trials were done outdoors, but again in a staged environment (this time in a park) with invited participants. The full development process is reported in two master theses [14, 27].

This design process ensured that the prototypes themselves were robust, provided legible feedback, and showed potential for supporting open-ended play. But in relation to the goals of DigiFys, the critical stage of trials was the integration of the prototypes into the landscape, where we

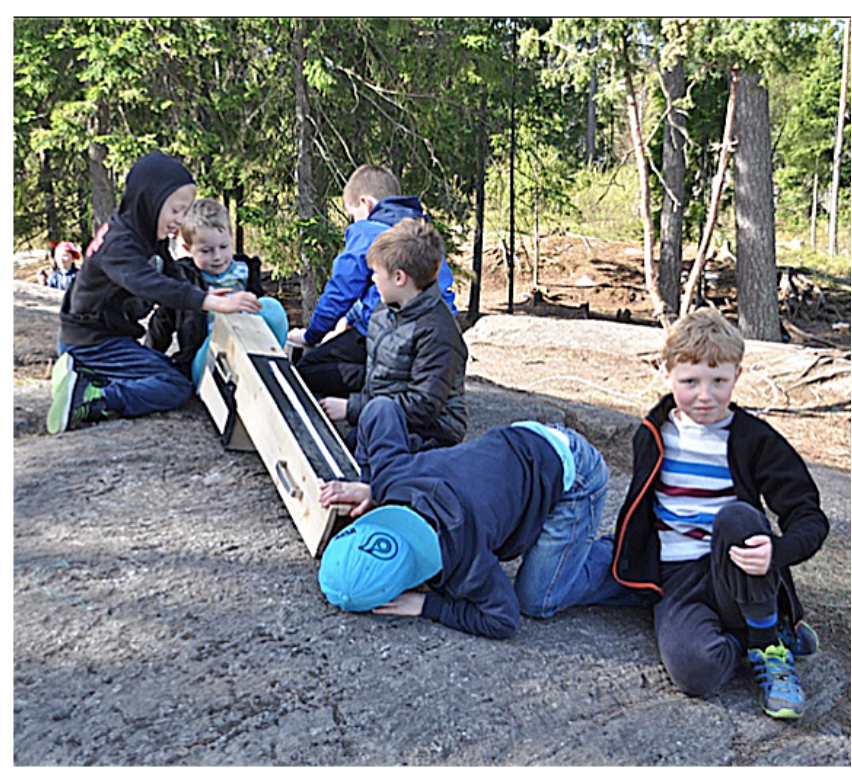

Figure 1: The tube.

could begin to study how play emerges in the interaction between landscape and the interactive installations. This is what is reported on in this article.

\section{ARTEFACT AND INSTALLATION DESIGN}

The interactive artefacts developed in the project share common design goals: they are designed to invite openended play [7] and to be possible to integrate in landscape architecture. They are also designed to be combinable. In the schoolyard trials, two prototype designs were used in different versions and settings.

\section{The tube}

The tube prototype is shown in Figure 1. The tube registers when objects, such as water, stones and twigs, are being put through and can recognize certain qualities of the objects, in the prototype like liquidity, noise, and movement. Feedback is provided by the tube itself, but was also integrated into other elements of the installations in the form of sound and light.

Physically, the tube is a square shaped wooden shaft. The length and other form factors of the tube can be adapted to the location where it is installed. Each tube is equipped with a water-sensor, an infrared barrier and a vibration sensor. Each of the sensors senses different qualities in the objects being thrown through the tube. The water sensor senses liquidity, the vibration sensor senses if the object causes more than light vibrations in the tube (typically related to the weight of the object). The infrared-barrier is triggered for most objects that pass through the tube. Through the use of different sensors, the tube reacts in different ways to different materials passing through. This is intended to broaden the experience for the children and invite them to explore and engage with the tube in different ways. The tube itself features both audio and visual feedback. 


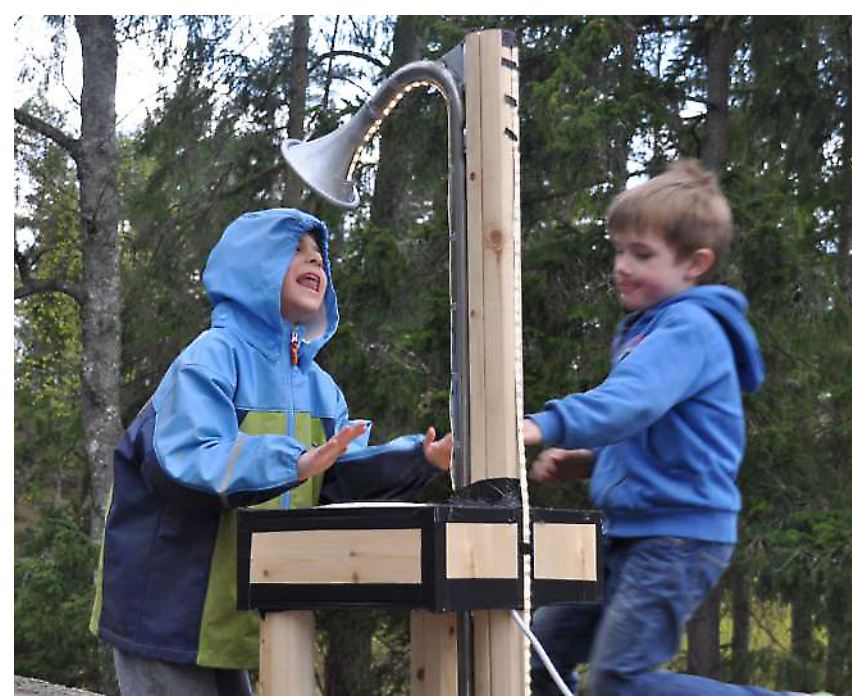

Figure 2: One of the communication nodes (mountain setting).

The tube projects a continuous soundscape around it, that gets more intense as the tube is used more and tunes down when the tube is used less. Each sensor also triggers its own sound. Visual feedback was mounted on the tube itself, and takes the form of a sequence of RGB LEDs on the top of the tube. Just as the ambient sound landscape reacts to the intensity of play, the LEDs show a pulsating animation, where the pulsation frequency increases when the tube is used intensely. When a sensor is excited, the LEDs show a falling animation to mimic the object falling through the tube. Each sensor is represented by a different colour on the LEDs.

\section{Communication nodes}

The communication nodes are shown in Figure 2. The communication concept was intended to enable children to communicate verbally with children in other places. In the trial three communication nodes were used that differed in visual appearance and form factor, to inspire multiple forms of interaction with the nodes.

The functionality of the controls was identical for all three communication nodes, and specifically designed for the project. Each communication node has two call buttons, each corresponding to one of the other two nodes. When a button is pushed, the communication channel to the respective node is opened. The nodes are identified with icons on the buttons resembling their physical appearance. This mode of communication is a hybrid between the protocols used in a telephone and a walkie-talkie: it has the simplicity of the push-to-talk interaction of a walkie-talkie, but establishes a two-way channel in the same way as a phone call. The prototypes also allow both buttons to be pushed at the same time, so that the speaker can speak to both nodes at once.

The state of the communication is conveyed through light and sound. When a communication channel is opened and closed, this is signalled by two distinctive sounds. The sounds are played both at the sending and at the receiving node. A ring of LEDs encircles each button, and is used to indicate its status through different animations. When communication is idle the light slowly pulsates, resembling the breathing of a person in rest. When communication is received, the LEDs of the respective button pulsate quickly. When there is outgoing communication, the lights are on permanently. When there is both incoming and outgoing communication there is a very light quick pulsation with an overall high brightness of the LEDs, combining the characteristics of the separate incoming and outgoing states.

In a similar way, multiple LEDs using the same animation schemes are installed at different places in the communication nodes.

\section{Installing into the environment}

While the interactive designs offer some inherent play opportunities, their purpose is to be integrated into an outdoor environment. The tube is specifically designed to interact with natural materials such as water, stones, twigs and pinecones.

In this article, we present and reflect upon the results from field trials with the prototype in a schoolyard of an elementary school south of Stockholm. The selected schoolyard was large, with multiple play areas with different landscape characteristics, including a natural forest, as well as a more traditional built playground. This created an ideal setting for exploring multiple ways to integrate interactive technology into the landscape.

\section{Pre-study}

Before the installations were put in place, the children playing in the schoolyard were observed over two of their recesses. Children led walking tours were also conducted with three groups of four children, the children were asked about their favourite and least favourite play areas as well as for their typical play practices in the schoolyard. This pre-study was necessary to sensitise the designer team for the playground and select locations for the installations as described above, in much the same way as the larger scale DigiFys landscape design process is informed by the target location. The pre-study also provided a useful backdrop for understanding how the children's every day practices were influenced by the installations.

\section{Selecting the installation locations}

The locations chosen for the installations are depicted in Figure 3 . The places were chosen after the child-led walks [4] with children from the school, who told us about their play activities and their favorite and least favorite play areas. Two settings were selected for the installations, here referred to as the 'mountain setting' and the 'water setting': The 'mountain setting' was located high up on a hill in the forested area of the school yard, and the 'water setting' was located in an open area in direct conjunction with a small water canal that runs through the school yard. The mountain setting was 


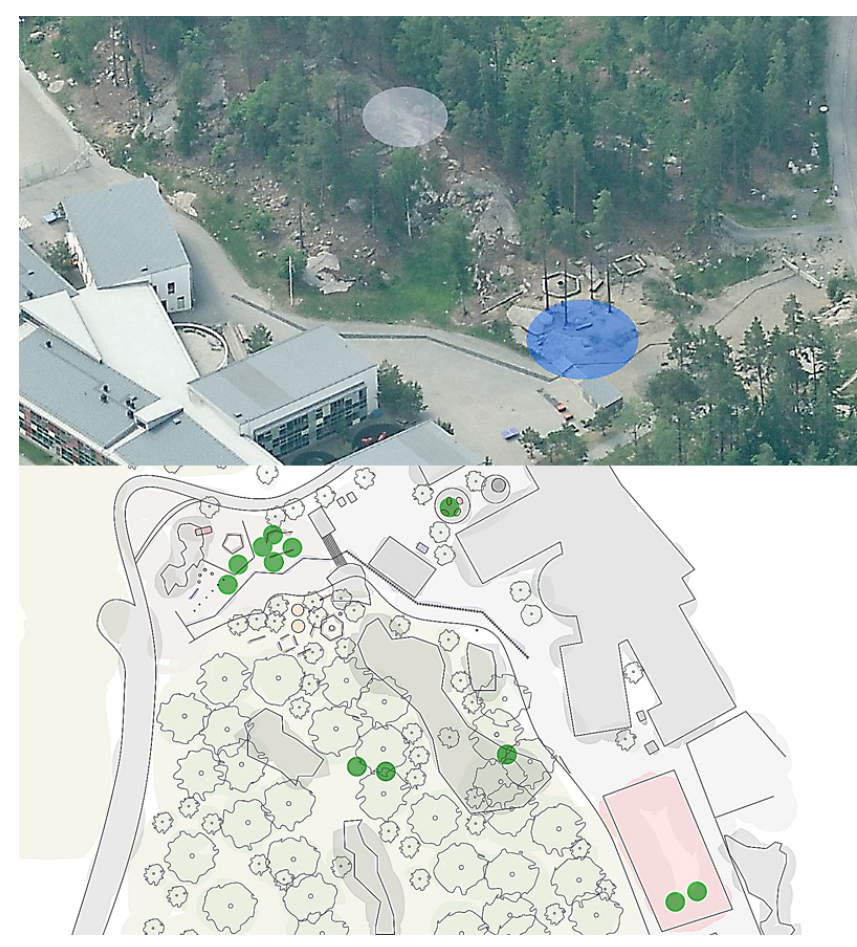

Figure 3: The installation places (top, photo). The chosen spots lie close to, but not exactly at, the favourite play spots as indicated by children (bottom, map).

located in what the children call 'the forest', a popular area for fantasy play and building huts. The 'water setting' is partly in the constructed part of the schoolyard, right at the forest border. Both locations were equipped with a tube and a communication node. For comparison, two portable versions of the tube and the communication node were also created.

\section{The mountain setting}

The high location as well as the forest inspired the installations in the mountain setting. The communication node was located at an open space on top of a cliff, with a clear view over the whole schoolyard. It was placed to be

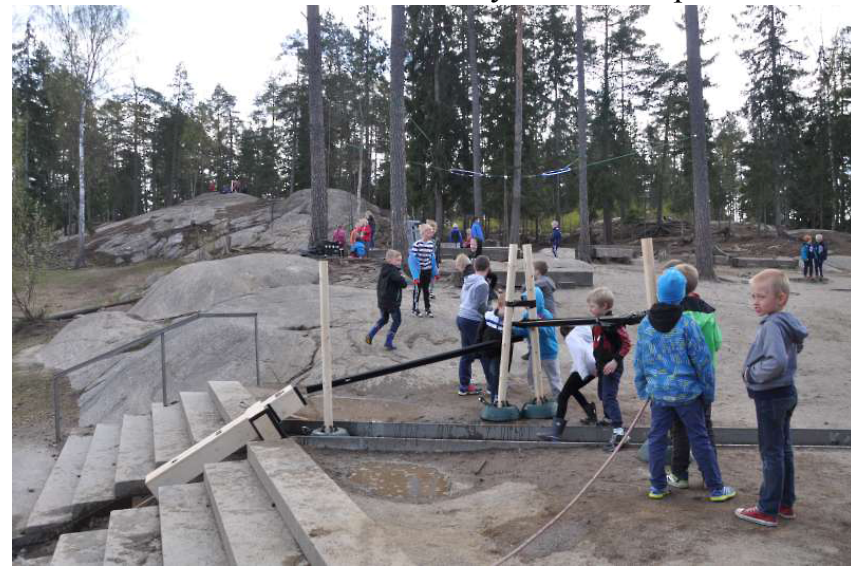

Figure 4: The tube installed at the water location.

an eye-catcher from anywhere in the yard. Similarly, while being up on 'the mountain', a player would be visible from the whole schoolyard. The main element of the mountain communication node was a speaking funnel, known from traditional playgrounds. A microphone was placed in the funnel. At children's waist height, a panel was installed for the buttons. Underneath this panel was a compartment for the output loudspeakers for the communication sounds and other electronics. LEDs were installed vertically along the speaking funnel on the front and backside.

The mountain tube was made very long. It had a total length of 4.5 meters ( 15 feet), going down a steep part of the cliff down in to the forest. Thus, it was taking advantage of, and emphasizing the challenging steep terrain that the children would be playing in. The sounds of the tube were consistent with the mountain theme, with different rock and gravel sounds. The mountain tube did not feature any visual feedback.

\section{The water setting}

The second setting was inspired by the presence of the water canal, and the opportunities it offered for water play. This affected in particular the installation of the water tube. The water tube was placed in a section of the water canal where there was a staircase connecting a higher and a lower level of the schoolyard. This enabled the slanted position necessary to throw things down the tube. The tube was extended with open rain gutters, attached to poles (Figure 4). These rain gutters allowed children to let objects or water take a detour before travelling through the tube.

The sounds triggered by the sensors were also inspired by the water theme. The infrared sensor triggered the sound of a water drop falling, the water sensor triggered the sound of flushing water, and the vibration sensor would sound like a big rock plunging in a lake.

The communication node in the water setting was completely integrated with the physical environment (Figure 5). It was placed on the border between the organized schoolyard and the forest. The buttons activating a call were made large, thirty centimetres wide, and low and cylindrical of shape. They were placed on the ground, to be

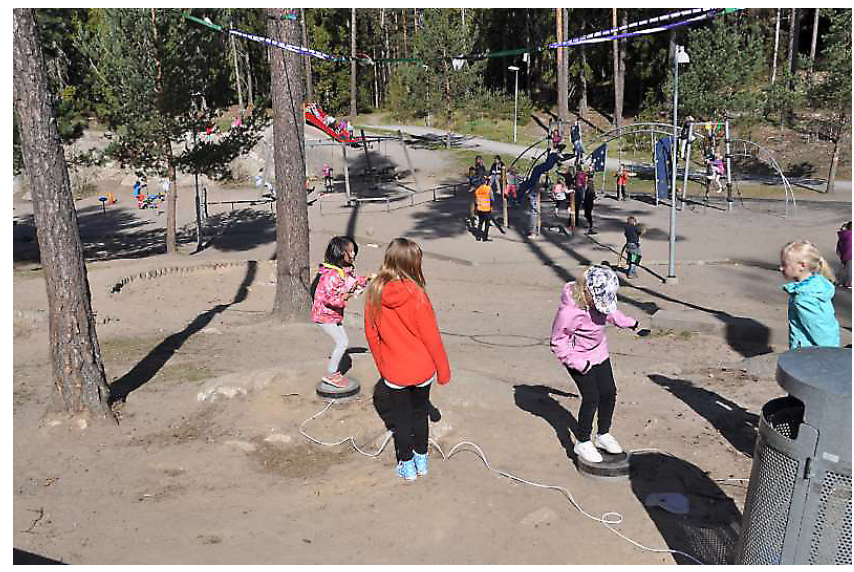

Figure 5: The communication node at the water. 


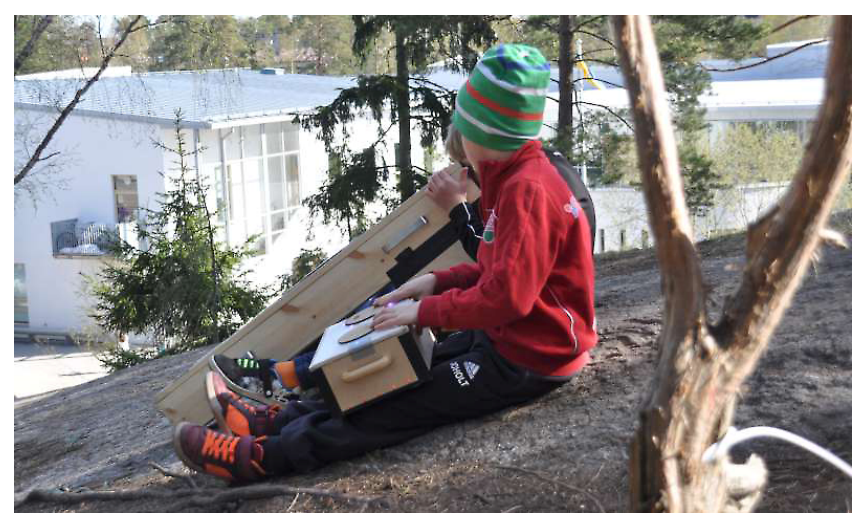

Figure 6: The two portable nodes. The tube in the background, the communication box in the front.

triggered by stepping upon them. Visual feedback was presented both through the prototype's standard rings of LED surrounding the buttons, and in the form of two rings with LEDs hanging above them. These showed the same animation as the LEDs around the button. The microphone was placed on the ground and could capture speech from both buttons. The speakers were hung next to the microphone between the rings.

\section{The Portable Nodes}

In addition to the two fixed installations, two portable versions of the prototypes were created (Figure 6). Their portable format allows them to be carried around and increase the children's opportunities to create their own playscapes around the prototypes, which provided a useful comparison to the two fixed installations during the study.

Since these prototypes are not supposed to be integrated into the environment, their sound and light feedback patterns were made adaptable. Dials mounted to both prototypes serve as theme selectors.

The portable tube is about 1 meter ( 3 feet) long, light enough for a child to carry, and fitted with 4 handles so that it can be shared. It features the same sensors as the other tubes. A lightweight speaker was built into the tube, and a RGB LED strip was fitted on the top.

The portable communication node is fitted into a small box with two buttons on top and two handles on the far end sides for portability. Apart from the LEDs encircling the buttons, additional LEDs around the bottom of the box convey the communication state. A microphone and a portable speaker are built in the box, each with a dedicated opening in the front.

\section{STUDY SETUP AND ANALYSIS}

The evaluation of the installations comprised four days of direct observation while the children in the school were offered free access to all of the installations during their normal recess time in the schoolyard.
The primary form of data collection was note taking on A3 size paper maps of the playground. This form of note taking emphasised the spatial and locative nature of the observations, in relation to the installations as well as to the playground in general. Whenever an interesting interaction, a special play event or anything else notable happened, the respective location was noted down and labeled with the time it happened, duration, number of participants, age group and gender of the involved children for each play event. The observation notes were guided by the following three questions:

1. What type of play happens in the schoolyard?

2. How does the landscape with our prototypes affect the play?

3. How is natural material used in the play?

Example notes are shown in Figure 7.

For ethical reasons, the audio-visual documentation was restricted to photographing play situations. All photos were cleared for publication with the school dean for the field trial and with the children's parents for the pre-study. No video or audio recordings were taken.

The data was collected over four days and a total of 11 recesses, during which a total of 900 interactions with the artefacts were observed. The study used a qualitative yet rigorous method for analysis, grouping these observations into clusters. Three researchers collaborated in performing this analysis.

The primary mode of analysis concerned qualitatively coding observations of play into play types, relating these to the locations in which play occurred. In line with studies performed by de Valk et al. [8], the aim was to distinguish between invitations as the initial attraction of an installations, explorative play when the children engage with an installation to figure out its play capabilities, and immersive play when children were deeply engaged in structured play. Following Frost [11], the play activities were further classified according to common playground play forms. While classification constitutes a simplified

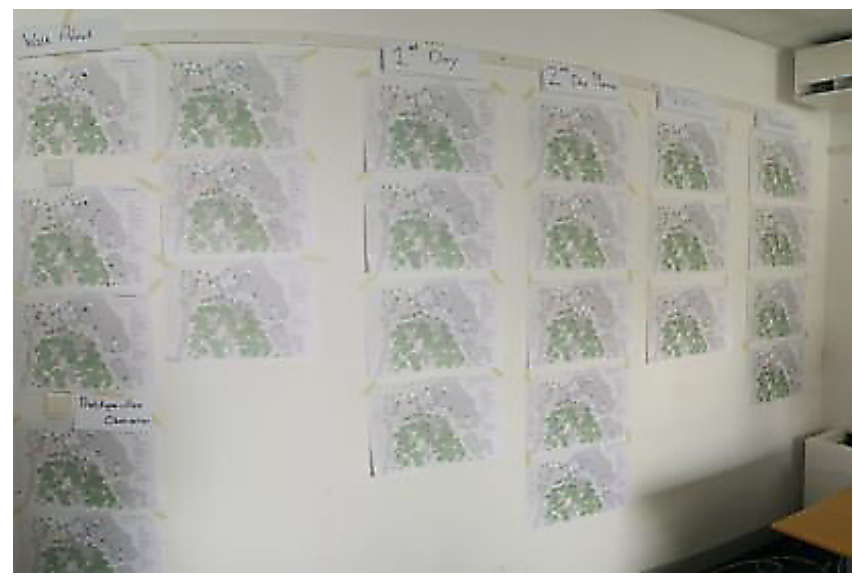

Figure 7: Field trial notes organized for analysis. 
version of developmental models of play [24, 25], it corresponds to what readily can be observed in a playground and is for that reason well suited to the form of documentation employed in our study. It should be noted that while the observations below are representative of interesting and recurring behaviours, the qualitative methodology motivates the representation of these through detailed descriptions of selected examples rather than numbers.

In addition to this classification, individual observations that stood out as particularly significant were identified. This allowed us to create a nuanced perception of the observed play activities, incorporating aspects that would not be captured by the simplified classification.

\section{OBSERVATIONS AND ANALYSIS}

The results show that the affordances of the landscape surrounding the prototypes defined the play patterns that appeared in multiple ways. In particular, the physical shape of the landscape, and the availability of natural materials shaped the play. Results also show that the interactive prototypes invited children to explore them to a large extent and to play in the area surrounding the prototypes.

\section{Landscape}

\section{Invitations}

We could see that the installations presented attractive invitations to play. Typically, children would start to play when they heard action-triggered sounds, be it a communicated message or the sound feedback from a tube or a communication node. The physical appearance of the installations also functioned as invitation, in particular with the mountain setting. Finally, the installations feature a 'honeypot effect' [3] children playing with an installation function as a strong attractor for other children. The honeypot effect was enhanced by the way most of the installations used sound to communicate play intensity.

The communication station with the funnel on top of the mountain fulfilled the expectations of inviting play. The affordance of the funnel invited children to speak and sing into it. These play patterns continued throughout the week. Giving speeches ('Dear fellow citizens...") was part of the performative play in this stage-like place on top of the mountain

\section{Running up and down the hill}

The design of the mountain tube, together with the affordances of the steep slope of the mountainside and loose forest materials, made the play with this tube very physical. The children were using hands, arms, feet and legs to try to push stones through the tube, to de-clog it and to excite the sound and light feedback. In the process of doing this they were running up and down the slope, using the tube as a slide and they lifted the whole tube and bounced it against the rock to get the stones through.

The typical play pattern around the mountain tube was a distributed activity around the lower and upper ends of the

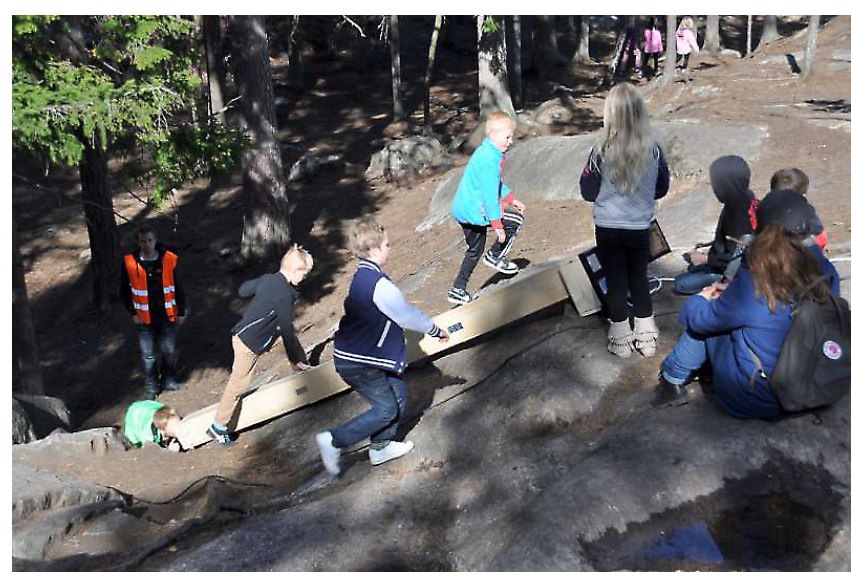

Figure 8: Running up and down, and playing in both ends of the tube.

tube (Figure 8). One or more children were putting in objects at the top, while another group of children were at the bottom to return the material as it came out of the tube. Often, one child would be looking into the tube only to take away their head in the very last moment. Here, children explored the physical properties of both tube and landscape material in a challenging bodily form of engagement.

\section{The forest edge}

The water communication node was situated at the edge of the forested area next to the water canal and constructed play area. The setting and design of this node, with rings high up above the heads of the children resulted in imaginative play (can be seen in Figure 5). An interesting aspect of this installation is the way it mediated an aesthetic landscape experience, in the way standing on the communication buttons and looking up through the rings also made you see the treetops and the open sky. Play was also based on the affordances of the buttons, in a way totally disconnected from the communication concept. The buttons were used to jump on, to stand on, to sit on, to look up into the sky to see the flashing lights in the rings, and to listen to the sound feedback. Placing two large buttons next to each other invited children to do synchronized activities on both buttons: Jumping at the same time, playing air guitar together or switching positions from one button to the other at the same time. The children imagined multiple functions for this installation: It was said to give a tickling feeling in the tummy, to create hunger, to be able to read thoughts, to be a teleporter, a time machine, an "alien thing", and many other things.

\section{Side play}

The interactive installations also affected, and inspired, play activities in the surrounding landscape. This happened in particular in relation to sound effects. This, we observed in relation to the ambient soundscape generated by the mountain tube. This tube used weather sounds to indicate intensity: as the activities with the tube increased, the weather condition reflected by the soundscape in the mountain tube changed from birdcalls, over rain to 
thunderstorm. Sometimes children, mostly girls, would be sitting under the speakers, listening to the bird calls and the changing weather conditions. On one occasion, a group of boys was playing in a hut in the forest close to the tube, while another group of children were playing with the tube. As the sounds from the tube changed to thunderstorm, one of the boys in the group playing in the hut said: "Load the cannons, there's thunder and rain on the way!" This is one of the few instances of imaginary play we saw related to this particular installation; the soundscape carried play value on its own in a more subtle way than the offered interactivity.

However, sound effects were also sometimes problematic and caused disruptions. This we observed in particular in relation to the communication nodes. Frequently, children were trying to establish communication by shouting "Hi! Can you hear me?" or "Who are you? What are you doing?" These communication attempts sometimes disrupted play next to the receiving station. We observed in particular one boy who was playing together with a group of children next to the water communication node. Whenever there was a call, he went to answer, but would just say "Hi!" and then return to his play with the rest of the group. The prototypes coerced him into responding, but his engagement was reluctant and as a result, no communicative play emerged with the other station. Another boy in the same group would instead repeatedly shout: "Shut up!" when somebody was contacting the station.

There was a lot of physical movement between the two stationary communication nodes. When children understood that they were contacted from another node they also wanted to speak, and ran between the nodes to be able to both talk and listen to each other (a common misunderstanding was that the communication worked only one way). Even when the functionality was fully understood, children would discuss who would go to which station or tell each other "come here", "you go there" or

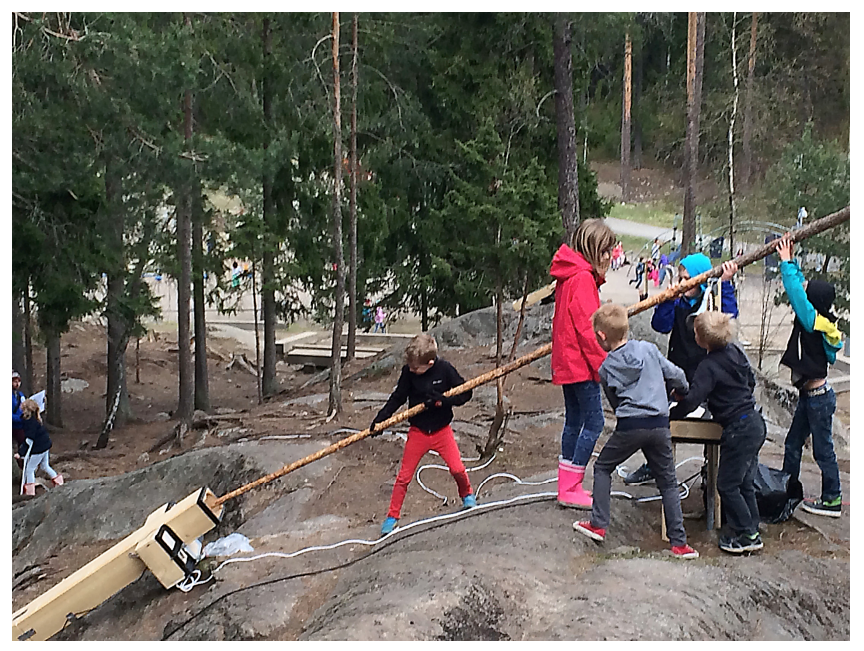

Figure 10: De-clogging the mountain tube.

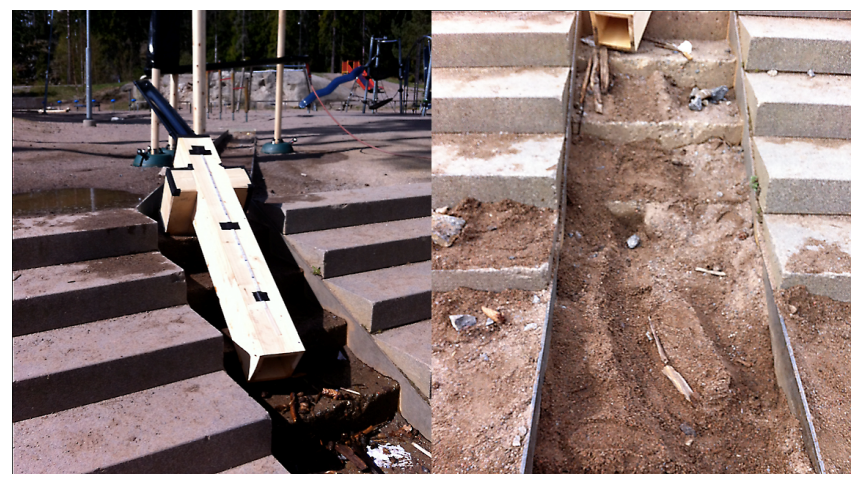

Figure 9: Playtraces at the water tube. The children have left stones and branches at the tube. The rightmost image shows how the track for rolling objects was extended in the sand below the tube.

"I'm coming to you". It seemed like distributed play was not organised through the nodes, but organized and agreed upon in physical meet-ups. This way, the installation of distance communication created physical movement rather than diminished it.

\section{Natural Materials}

\section{With and without water}

Water is one of the most play-inspiring materials in outdoor play [17]. Consequently, the water tube featured a lot of immersive play on the first day, when it was possible to play with running water. However, during this day the tube itself played a lesser role in water play than the two rainwater gutters. The play changed significantly in the following days when there was no water supply. Now, children used different materials to evoke the sounds and lights of the tube. The children focussed on spherical objects, such as tennis balls, marbles and pinecones. The sand available in the area played an important role at the water tube. It was thrown through but also used to extend the tube itself. A complex open-ended rule-based game emerged, where the children extended the end of the tube using sand and twigs, constructing their own track in the empty water canal through which a ball had to roll. They kept trying out different starting points in the rainwater gutter in order for the ball to reach that particular point. The use of natural materials is clearly visible in the play traces left at this installation (Figure 9) as well as with the mountain tube.

\section{De-clogging}

A very common interaction with the mountain tube was the communal de clogging of the tube as large objects got stuck on their way down. This activity was not considered something to avoid, but took up a large share of the playtime around the mountain tube and was a highly cooperative activity. Children used large branches of two to three meters length found in the forest to poke inside the tube to get objects unstuck (Figure 10). These were planned and coordinated actions accompanied by comments such as "if we throw in three stones at once, it will come out". 


\section{Ambulatory Play}

The portable prototypes featured some modes of play that were unusual for the fixed installations. Both the portable tube and the communication box tended to be used by one or a few children at a time, thus primarily supporting solitary play and seemingly a feeling of ownership (see Figure 6) .The mobile prototypes proved to be better suited for imaginative play than the fixed installations, and the children that developed immersive play strategies came back to play with them repeatedly on different breaks and days.

An example of imaginative play emerged when a boy found out that the installations had been placed in the schoolyard as part of a research project. This child used the tube intensely for the whole testing period during his breaks, exploring the interaction possibilities with the tube and imagining himself as a researcher, using the tube as a research instrument. One boy used the communication box as an announcement station, repeatedly commanding "To the office!" at different positions.

While the portable prototypes were carried around, their action radius was still rather limited. The children did not carry the prototypes far away, and on one occasion some children even returned the tube to a researcher when they found it in the forest. The landscape interacted with the portable prototypes in how the children used the landscape while exploring the prototype (i.e. using a tree stump as the research table) and they explored the landscape using the prototype by placing it in different positions and angles.

\section{DISCUSSION}

\section{Versatility}

The observations present some indications as to how the playscape may be enhanced by interactive technology. In particular, we saw that adding interactive elements to the landscape can increase the versatility of a location. Through interactivity, the locations are enriched to support a wider range of play activities than before.

This was particularly obvious with the water tube, which was installed in a location that would be rather impoverished without its presence especially when there was no water running in the canal. Since water has a high play value in itself, the interactive installation was less important when water was available. But when there was no water, which for this particular location would be the normal situation, the interactivity enriched the same place with a range of play activities. These were created by the design for open-ended play, but also by the way in which in particular the sound feedback created strong invitations to participate in play.

The other installations were installed in locations that already supported a wide range of play activities. Still, these also created a range of new play opportunities. It is particularly interesting to note that they inspired some synchronized, collaborative group play. The fixed communication nodes created a play activity focused on collectively organized communication, and associated to that, some intense running up and down the hill. The mountain tube created some interesting collective and synchronized play related to throwing natural material through the tube and de-clogging it. These play activities were closely related to the interaction offered, such as that throwing big and heavy stones into the tube triggered a different sound than throwing light objects. In the case of the communication nodes, much of the synchronization and running was created by the need to decide who was to speak, and who would listen.

While nature offers versatility in and of itself, the neighborhood close to home that DigiFys targets is typically much less versatile. The schoolyard studies give us reason to believe that an integrated design approach to landscape architecture and interaction design will be able to provide a rich play environment also in such settings.

\section{Invitation and Exploration but little Immersion}

In literature on interaction design for play, it is common to look upon long-term engagement as the end goal of any interactive design. In our observations, we found that the digital installations were effective in offering invitations, in particular through sound. To some extent also through light, although, as all playtesting was done in broad daylight and the effects of light are likely to be more present in dusk or at night, it is hard to draw any clear conclusions from this.

We were able to observe a wide range of functional and explorative play, where the children engaged in activities directly related to the physical form and function offered by the installations. However, there is also an observable novelty effect related to such play activities, in how they decline once the installations have been in place a couple of days. By contrast, immersive play was relatively rare in our study.

This should not be seen as an indication that the designs were unsuccessful, but is typical of how play activities are shaped by schoolyard environments as well as designed playgrounds, with their time limits for play (school breaks and parent's schedules). Typically, children tend to roam the schoolyard, rapidly moving from one play activity to another. In such settings, the successful design is rather one that offers recurring play, when children come back to an installation over and over again, during the same visit or multiple visits. We saw multiple examples of such recurring play in relation to both the fixed and the mobile installations.

\section{Adaptability}

One of the goals of the design was that the interactive prototypes would be adaptable, in two important ways. Their exact design could be adapted to the location of installation, and the strive for open-ended play was intended to offer children ways to invent their own games and play activities based on the offered interactivity. We 
also saw multiple forms of play emerge around the installations, such as the ball game at the water tube and the dislodging of stones at the mountain tube.

However, we had intended the prototypes to support symbolic fantasy play; the tube could for example have represented tanking a car, feeding an animal, throwing out waste through a waste chute or shooting a cannon. While it is possible that some such scenarios could have developed if the installations had been left in place for longer, it is a fact that we observed almost no such activities around the fixed installations. We did observe fantasy play in relation to the mobile installations.

One potential explanation for this effect was that openended interaction is not enough to sustain fantasy play in the outdoor setting. Compared to the infinite adaptability of nature, through its versatile physical affordances, abundance of varied materials, and ever-changing weather and climate conditions, open-ended interaction is a very limited design tool. A key insight was gained by looking at the playtraces such as the ones shown in Figure 9, around our installations as well as those left in other areas of the schoolyard. The traces illustrated how the children would constantly adapt their playtools and environment to their ongoing play activities.

Hence, a possible reason why the mobile installations were more successful in offering fantasy play was that they were, in fact, adaptable. These prototypes offered an opportunity for the children to adapt their sounds to their personal preferences. Furthermore, the fact that they were portable allowed the children to carry them to a location of their own choosing to integrate them in on-going fantasy play, such as when a boy declared that "this, I will bring to my hut"!

\section{CONCLUSION}

The schoolyard study presents many important insights concerning the integration of interactive technology into a playscape. We saw in particular that interactive technology is good at presenting play invitations, and that it is possible to capitalize on sound and light to this effect.

We saw opportunities for the use of interactive technology as a way to present more versatile play options in otherwise impoverished places, such as offering play at the gutter when dry. However, we also saw that raw nature is much more adaptable than raw interactivity, even when the installations are designed to offer open-ended play.

The long-term goal of DigiFys is to develop strategies for making interactive technology truly embedded into the landscape of the play environment. The schoolyard trials achieved this only to a limited extent. Most of the installations remained artifacts placed in the environment even though nature materials were used, and our trials give us reason to believe that this affected in particular their ability to foster sustained imaginative play. This is a challenge that we will continue to address in the second stage of the project.
The schoolyard trials have highlighted the dilemma of at the same time designing artifact-centered interactivity with the more holistic perspective of designing the playscape. The studies elicited some first steps towards addressing this dilemma and future research will focus on further integrating the design activities by landscape and interaction designers.

\section{ACKNOWLEDGMENTS}

We thank all the children that participated in the field evaluation at the school Balingsnässkolan and the staff at the school that helped us in the process of conducting the study there. This work has been funded by Sweden's innovation agency (VINNOVA).

\section{REFERENCES}

1. Ann C. Barbour. 1999. The impact of playground design on the play behaviors of children with differing levels of physical competence. Early Childhood Research Quarterly 14,1 (1999): 75-98.

2. Anne Bell, Janet E. Dyment. 2006. Grounds for action: Promoting physical activity through school ground greening in Canada. Evergreen.

3. Harry Brignull and Yvonne Rogers. 2003. Enticing people to interact with large public displays in public spaces. Proceedings of INTERACT, 17-24.

4. Sofia Cele. 2006. Communicating place: methods for understanding children's experience of place. Ph.D. thesis, Stockholm University Department of culture geography. Retrieved September 21, 2015 from http://www.divaportal.org/smash/record.jsf?pid=diva2 $\% 3$ A $186613 \&$ dswid $=8$ 961

5. Swetha Chakravarthi. 2009. Preschool teachers' beliefs and practices of outdoor play and outdoor environments. Ph.D. thesis. University of North Carolina at Greensboro.

6. Rhonda Clements. 2004. An investigation of the status of outdoor play. Contemporary issues in early childhood. 5,1 (2004): 68-80.

7. Linda de Valk, Tilde Bekker, and Berry Eggen. 2013. Leaving room for improvisation: towards a design approach for open-ended play. In Proceedings of the 12th International Conference on Interaction Design and Children.

8. Linda de Valk, Pepijn Rijnbout, Tilde Bekker, Berry Eggen, Mark de Graaf and Ben Schouten. 2012. Designing for playful experiences in open-ended intelligent play environments. In IADIS International Conference Games and Entertainment Technologies. 3-10.

9. Linda de Valk, Pepijn Rijnbout, Mark de Graaf, Tilde Bekker, Ben Schouten, and Berry Eggen. Glowsteps-a decentralized interactive play environment for open-ended play. In Advances in Computer Entertainment, 528-531.

10. Ingunn Fjortoft, Sageie Josefein. 2000. The natural environment as a playground for children: Landscape description and analyses of a natural playscape. Landscape and Urban Planning 48 (2000) 83-97.

11. Joe L Frost. 1992. Play and playscapes. Delmar. 
12. Lawrence V. Harper, and Karen M. Sanders. 1975. Preschool children's use of space: Sex differences in outdoor play. Developmental Psychology 11,1 (1975): 119.

13. Henrik Hautop Lund, Thomas Klitbo, and Carsten Jessen. 2005. Playware technology for physically activating play. Artificial life and Robotics, 9, 4 (2005):165-174.

14. Caspar J.H. Heeffer. 2015. Long-term engagement in interactive playgrounds, Master thesis, Royal Institute of Technology, Stockholm.

15. Kenji Iguchi and Masa Inakage. 2006. Morel: remotely launchable outdoor playthings. In Proceedings of the 2006 ACM SIGCHI international conference on Advances in computer entertainment technology, 35 .

16. Petra Jarkiewicz and Ylva Fernaeus. 2008. In the hands of children: exploring the use of mobile phone functionality in casual play settings. In Proceedings of the 10th international conference on Human computer interaction with mobile devices and services, 375-378.

17. Rachel Kaplan and Steven Kaplan. 1989. The experience of nature: A psychological perspective. CUP Archive.

18. Kyle Kilbourn, Larisa Sitorus, Ken Zupan, Johnny Hey, Aurimas Gauziskas, Marcelle Stiensta, and Martin Andresen. 2004. Exploring narratives for physical play: A pop-up guide to an interactive playground. In Technologies for Interactive Digital Storytelling and Entertainment, 240-245.

19. Gunilla Lindholm. 1995. Skolgården. MOVIUM sekretariatet för den yttre miljön, vid Sveriges lantbruksuniversitet i Alnarp.

20. Fredrika Mårtensson. 2009. Lek i verklighetens utmarker. I eds. M. Jensen and A. Harvard. Lek för att lära: Utveckling, kongition och kultur. Lund: Studentlittaratur. 163-188.

21. Simon Nicholson. 1971. How not to cheat children: The theory of loose parts. Landscape Architecture 62 (1971) 30-35.

22. Narcís Parés, Anna Carreras, and Jaume Durany. 2005. Generating meaning through interaction in a refreshing interactive water installation for children. In Proceedings of Interaction Design and Children, 218223.

23. Narcís Parés, Jaume Durany, and Anna Carreras. 2005. Massive flux design for an interactive water installation: water games. In Proceedings of the 2005 ACM SIGCHI International Conference on Advances in computer entertainment technology.
24. Mildred B. Parten. 1932. "Social participation among pre-school children." The Journal of Abnormal and Social Psychology 27,3 (1932): 243-269.

25. Jean Piaget. 1951. Play, dreams and imitation in childhood. Vol. 25.

26. Ronald Poppe, Robby van Delden, Alejandro Moreno, and Dennis Reidsma. 2014. Interactive playgrounds for children. In Playful User Interfaces, 99-118.

27. Andreas Rau. 2015. Digitally Augmenting the Built Environment to Mediate Play. Master thesis, Royal Institute of Technology, Stockholm.

28. Yvonne Rogers and Sara Price. 2004. Extending and augmenting scientific enquiry through pervasive learning environments. Children Youth and Environments, 14,2 (2004):67-83.

29. Susanne Seitinger. 2006. Animated props for responsive playspaces. $\mathrm{Ph}$. D. Dissertation. Massachusetts Institute of Technology,

30. Susanne Seitinger, Elisabeth Sylvan, Oren Zuckerman, Marko Popovic, and Orit Zuckerman. 2006. A new playground experience: going digital? In Extended abstracts on Human factors in computing systems (CHI’06), 303-308.

31. Szczepanski, Anders, and L. O. Dahlgren. 1997. Utomhuspedagogik. Boklig bildning och sinnlig erfarenhet. Linköpings Universitet, Linköping, Sweden.

32. Janienke Sturm, Tilde Bekker, Bas Groenendaal, Rik Wesselink, and Berry Eggen. 2008. Key issues for the successful design of an intelligent, interactive playground. In Proceedings of the 7th international conference on Interaction design and children. 258265.

33. James Talbot and Joe L. Frost. 1989. Magical playscapes. Childhood Education 66,1 (1989): 11-19.

34. Daniel Tetteroo, Dennis Reidsma, Betsy Van Dijk, and Anton Nijholt. 2012. Design of an interactive playground based on traditional children's play. In Intelligent Technologies for Interactive Entertainment, 129- 138 .

35. Gordon Tiemstra, Renée Van Den Berg, Tilde Bekker, and MJ de Graaf. 2011. Guidelines to design interactive open-ended play installations for children placed in a free play environment. In Proceedings of the international conference of the digital research association (DIGRA). 1-17.

36. White, R. \& Stoecklin, L. 1998. Children's outdoor play and learning environments: returning to nature. Early Childhood News 10, 2(1987): 24-30. 